\title{
Discussion of Robert S. Kirsner, Qualitative-quantitative Analyses of Dutch and Afrikaans Grammar and Lexicon Introduction
}

Ronny Boogaart \& Ad Foolen

NT 20 (2): 215-217

DOI: 10.5117/NEDTAA2015.2.BOOA

From the moment Robert Kirsner's book Qualitative-quantitative Analyses of Dutch and Afrikaans Grammar and Lexicon (John Benjamins, 2014) appeared, it was clear to us that this occasion should not go unnoticed in the journal Nederlandse Taalkunde/Dutch Linguistics. Organizing a discussion of the book was, in our view, the perfect way to pay tribute to Kirsner's lasting contribution to linguistics in general and to the description of Dutch in particular. To be sure, not all of the research conducted by Kirsner since the late nineteen sixties is covered by the present volume; lacking most conspicuously is his earlier work on the verb zullen (Kirsner 1969), on presentative sentences with er (Kirsner 1972, 1979) and on the (pseudo) passive (Kirsner 1976/1977). However, the range of topics addressed in this book is still impressive: demonstratives, pragmatic particles in the context of imperatives, a detailed analysis of the idiom ho maar, progressive constructions and indirect object constructions. ${ }^{1}$ At our request six commentaries were written by experts on specific topics dealt with in the book, and Kirsner was then given the opportunity to respond to all of them in a concluding paper.

Not only the multitude of topics discussed, but also the specific approach advocated by Kirsner provides more than enough food for thought, as the discussion will make clear. From the start of his career, Kirsner's approach has been quite an original one in Dutch linguistics, both from a

1 A convenient overview of the contents of the entire book, including Chapter 3 on demonstratives in Afrikaans not further discussed here, is provided by Kirsner himself in the first section of his response. 
theoretical and from a methodological point of view. At a time when native speaker intuitions were considered as the main data for linguistic theorizing, Kirsner based his analyses on language use data, mainly texts. Intuitions were elicited in an experimental context, testing hypotheses that were generated by corpus analysis. The way in which Kirsner uses questionnaires and quantitative data from texts is critically assessed in the contributions by Egbert Fortuin and Jeroen van de Weijer, whereas Fons Maes and Monique Flecken specifically point out the need to complement Kirsner's research with new methodologies that have been developed in the past decades.

While, methodologically, Kirsner's approach accords very well with the usage-based methodology advocated in modern Cognitive Linguistics, Kirsner has always kept a critical distance to Cognitive Linguistics at the theoretical level, see the concluding section 7.3 in his book, called Columbia School and Cognitive Grammar. It is indeed the Columbia School, initiated by William Diver at Columbia University, which is Kirsner's theoretical home base. In this approach, a language is seen as a system of rather abstract signs, which typically have an instructional meaning, i.e. the signs guide the hearer to the message that the speaker wants to convey, at the same time guiding the hearer to pay a varying degree of attention to different aspects of the message. The different signs constitute a system with differential values. Labels like 'structuralist', 'semiotic', 'functionalist' and 'communication-oriented' all apply to the theoretical outlook of Columbia School research. Now, the postulated abstract character of the signs goes hand in hand with a preference for monosemic analyses ('one form, one meaning'). In this respect, there is a difference with Cognitive Linguistics, which prefers 'richer' (polysemic) descriptions, in which different uses of the same sign are considered as part of the linguistic knowledge of the native speaker, not as different interpretations-in-context, as the Columbia School sees it. The issue clearly has to do with the division of labor between semantics and pragmatics, which will stay on the agenda of linguistics for a while. In the discussion, Bob de Jonge presents a more in-depth description of this 'functionalist struggle', while Dirk Geeraerts makes the case for polysemy, specifically applied to Kirsner's analysis of ho maar!

It is interesting to note that with respect to the degree of abstractness of linguistic knowledge, the Columbia School shows affinity with generative approaches. In both frameworks, the knowledge of language is considered as an abstract system, which is at quite a distance from language use. The two approachers differ, however, when it comes to the role of language use as a methodological access to the abstract system. For Columbia School 
researchers, language use offers the point of departure for developing hypotheses about how the system is structured, whereas generative grammar trusts intuitions and phenomena of language acquisition as providing the primary access to the object of study, being the language system. In contrast to Columbia School and Generative Grammar, Cognitive Linguistics positions the language system closer to language use, so that (quantitative) generalizations over language use data are rather easily accepted as being representative for the knowledge of native speakers about their language.

These short introductory remarks are just meant to make clear that the Columbia School represents an interesting position on the methodological and theoretical parameters of linguistic theorizing. Dutch linguistics has been in the lucky circumstance that through the work of Kirsner this position has been part of its discours since the 1970s. We thank Monique Flecken, Egbert Fortuin, Dirk Geeraerts, Bob de Jonge, Fons Maes, Jeroen van de Weijer and, of course, Bob Kirsner, for their cooperation in this project. We hope that the following critical discussion will contribute to the necessary reflection on the best practices in linguistic research, Dutch linguistics being part of that enterprise.

\section{Bibliography}

Kirsner, Robert S. (1969). The role of zullen in the grammar of Modern Standard Dutch. Lingua 24: 101-154.

Kirsner, Robert S. (1972). On deixis and degree of differentiation in Modern Standard Dutch. Columbia University, PhD.

Kirsner, Robert S. (1976/1977). De "onechte lijdende vorm". Spektator 6: 1-18.

Kirsner, Robert S. (1979). The problem of presentative sentences in modern Dutch. Amsterdam/New York/Oxford: North-Holland Publishing Company.

\section{About the authors}

Ronny Boogaart, Leiden University Centre for Linguistics. E-mail: r.j.u.boogaart@hum.leidenuniv.nl

Ad Foolen, Radboud University, Centre for Language Studies. E-mail: a.foolen@let.ru.nl 